\title{
SERVICE LEARNING INTEGRATED WITH FOREIGN LANGUAGES LEARNING: PROMOTING TRANSVERSAL COMPETENCIES
}

\author{
Dana Hanesová \\ Department of Pedagogy, Faculty of Education, Matej Bel University (Slovakia)
}

\begin{abstract}
In this article, the author will present an innovative way how to develop students' foreign language communicative and intercultural competence alongside with a whole set of transversal competencies via an innovated version of foreign language courses. They may be attended by both university students or secondary school students. The basic idea of such a course, in our case called "Global Encounters in Local Settings", is giving students space to create a service-learning project for a community. Students have to work in linguistically and ethnically mixed groups. Each group decides to about the focus of their project and the procedures of its implementation. Via these cooperative projects accomplished while using various foreign languages - suitable also for online learning space, the students can develop various transversal competencies, such as critical and reflective thinking, plurilingual and intercultural competence, problem-solving, team-work skills, interpersonal and other social competencies, willingness to take risks and seek challenges, leadership development skills, time management and planning skills, inclusive approach, and active citizenship. The first version of such course was tested on several groups of university students in Slovakia (in 2020). The post-tests and reflections after accomplishing this course showed evident growth in the above-mentioned competencies.
\end{abstract}

Keywords: Innovation, service learning, transversal competencies, foreign language learning.

\section{Introduction}

The purpose of our paper is to point out one of the possible innovative ways of developing not only foreign language communicative skills, but also several transversal competencies of university students. It is also applicable to high school students.

It is necessary to realize that as the changes in a globally connected society accelerate, so do the requirements for university education outcomes and, in particular, the qualifications of university graduates. Universities in the Slovak Republic prepare students in accordance with the current European and National Qualifications Frameworks. However, the World Economic Forum reports (2016 and 2018) on the future of jobs show that there is a rapid change in the supply of potential professions, so graduates from all schools will soon have to take up new professions that are still being formed. According to the authors of these international reports, most education systems today provide "dead", too specific education. In the future, it will be necessary for graduates to be interdisciplinary prepared and equipped with broader, transversal competencies, which will enable them to solve a certain area of problems, taking into account all related and emerging contexts, both theoretical and practical. Of course, the need to be able to use more foreign languages remains a challenge, as foreign language and intercultural competencies actually open up access to the labor market for graduates of various levels of education.

\section{Key terms and theoretical outcomes}

Before presenting the implementation of our specific educational innovation focused on the development of competencies in foreign languages as well as transversal competencies, we consider it necessary to clarify these concepts, as well as the essential strategy of learning services. We dealt with the definition of these terms in our monograph (Kosová, Hanesová, Šukolová et al, 2019).

Transversal skills and competencies - The word connection transversal skills and competencies is often used as a synonym with the terms generic, key, transferable, global or even 21 st century skills or competencies. They all have the same essence but differ slightly in emphasis and purpose, and there are no precise definitions of their use. 'Generic skills' are skills that are important for work, education and 
life in general, applicable in various occupations (e.g., general communication, organizational, interpersonal or analytical skills and abilities). They are sometimes referred to as 'key competencies' and operate mainly in the relationship area between education and employment. The term 'transferable skills and competencies' emphasizes that these are competencies acquired in one context, e.g., in research, but they can be effectively used and further developed in another context e.g. in employment, or in business. Similarly to transferable competencies, the transversal ones are not related to one specific profession, but "they can be used in different situations and working conditions" (UNESCO - IBE Glossary, 2013). The terms transversal and transferable competencies can therefore be considered almost synonymous, differing only slightly in their emphasis. Transversal skills and competencies emphasize cross-sectionality in terms of the content; transferable skills focus more on transferability in terms of the process of individuals' careers. Since 2013, the term transversal skills started to be used also with the emphasis on humanity and holistic development of the personality of learners, at least within one UNESCO report. In this sense, transversal skills include e.g., "collaboration, self-discipline, resourcefulness, and respect for the environment" (UNESCO, 2015). To some extent, they are considered overlapping with the concept of global competencies, which, however, e.g. according to PISA 2018, relate in particular to the ability "to examine local, global and intercultural issues, understand and appreciate and worldviews, interact successfully and respectfully with others, and take responsible action toward sustainability and collective well-being."

For the purposes of this paper, focused on education, we will use the term transversal competencies, as a synonym for the term transferable competences. Both - as in the case of the other mention synonyms - consist of knowledge, skills, values, attitudes and will. The OECD Classification (2012) mentions an inspiring classification of categories of these skills, which we have used also in our innovation. According to this OECD document, it is possible to talk about the need to develop interpersonal skills, organizational skills, research competencies, cognitive skills, communicative and entrepreneurial skills (2012).

Global competencies necessary for the next generation of professionals include intercultural competence, which can be defined both as knowledge of culture but also the ability to show intercultural empathy, respect, tolerance, sensitivity, flexibility, the ability to negotiate and argue, try to understand, discuss and achieve consensus with others as well as the ability to communicate in several languages. Foreign language communicative competence - from the point of view of contemporary linguistic didactics - is focused primarily on the ability to communicate in a foreign language. The concept of communicative competence was coined by D. Hymes in his theoretical study (1972). By foreign language communicative competence, we mean the ability of students to use the acquired vocabulary, pronunciation and grammar in the way required by the socio-cultural context and linguistic system, through all four communication skills (listening, speaking, reading, writing) (Bérešová, 2009). Communicative foreign language competence "contains a static part, ie. complex multilayer knowledge, and a dynamic part, ie. the ability to use this knowledge in various communication contexts" (Nováková, 2020, p. 12). According to the White Paper on Education and Training by EU Commission (in 1995), we should have adequate communication skills in at least two foreign languages.

An innovation of foreign language teaching can be achieved in the case of a combination, or better to say, synergy of the goal - which is foreign language communicative and other transversal competencies - with the pedagogical strategy of service-learning. Service learning is based on the integration of learning processes with meaningful voluntary service to a community, ie it is literally about learning through service. It is a form of experiential learning, where learning occurs in a cycle of activities and critical reflection. It enables students to acquire meaningful learning experiences at the same time as implementing common community solutions to real problems of a particular community. Mitchell and Donahue consider the ideal service-learning experience related to the involvement of students in the community, solving its specific problems, contributing to the real development of communities in particular. According to these authors, "students may see the community as a place of learning equivalent to the classroom or even more valuable than the classroom because knowledge and skills are gained in the context of hands-on use" (Mitchell \& Donahue, 2017, p. 464).

It should be emphasized that service-learning includes not only projects for the community, but also their creation in reciprocal relations with the community. The current concept of service-learning includes a critically-reflective practice of better understanding human dignity, oneself, culture, but also socio-economic, political and environmental issues, power relations and social responsibility, in a way emphasizing "the impact of global structures in local contexts. The key dimension of global service-learning is community building, and especially "the development of relational trust and mutual respect" ... It prioritizes the goals of "economic equity, equal partnership, mutual learning, cooperative and positive social change, transparency, and sustainability". It creates a space for building a "world that recognizes human dignity across nations" (Hartman \& Kiely, 2017, 322-324). 


\section{Empirical research of pedagogical innovation}

In this part we will move on to the practical application of the idea of a functional synthesis of a service-learning strategy with the development of transversal competencies. We will first describe this innovation in more detail and then present methods for examining its pilot implementation.

\subsection{Description of the pedagogical innovation}

In 2019, a group of language teachers across the faculties of Matej Bel University (MBU) in Banská Bystrica created a new foreign language course, Global Encounters in Local Settings (GELS), based on service learning strategy. The course was created within the broader project 'Plurilingual and intercultural edulab supporting university strategy of internationalization 'in Slovakia (project KEGA 004UMB-4/2019) which began in 2019 and ends in 2021. It has been offered as a selective subject for students of any Bachelor, Master and doctoral study programs at this university since January 2020. Information about this course, including its aims to develop plurilingual, intercultural and other, the above-mentioned transversal competencies of students, as well as an overview of the assignments and expected student's workload, was published on the MBU website. It was made public also on the foreign language website version, so that foreign students interested in mobility at UMB can also access it.

As we found out at the first GELS meeting with students, those who were interested in improving their foreign language and intercultural competence, learning about other cultures, as well as in acquiring transversal competencies applied for the course. So far, both domestic and foreign students (studying entire programs at UMB or mobility students) have applied for GELS in each semester.

The task of the students, working in linguistically and culturally mixed groups, was to analyze their socio-cultural background and to select a need of a certain community, and to prepare and implement a project fulfilling this need.

After the initial introductive and instructional meeting with the supervising teachers, the groups of students worked independently, using instructional worksheets. Teachers continuously monitored the work in groups. Together they met again for the final presentation of the students' group projects. Reflective diaries and group reports were written by the students throughout the creation and implementation of the project. During the final meeting in the whole class, the students presented their projects and their self-reflections in front of the teachers and the whole class, on the basis of which they were finally evaluated. The output of the course were projects created for the community of the city, for the community of foreign students as well as foreigners in the city of Banská Bystrica, and finally during the pandemic in general for foreign university students.

\subsection{Methods of data acquisition and data processing}

The GELS course was implemented during two semesters in 2020. The research sample consisted of 60 students in total (30 in the experimental group and 30 in the control group). The effectiveness of the implementation of the GELS course was verified by the so-called mixed research methodology of data acquisition and data processing:

a) By pre-tests and post-tests of plurilingual and intercultural competence in both experimental and control groups. These questionnaires were constructed by the KEGA team researchers, they consisted of open and closed questions. Closed questions were evaluated through descriptive statistics and open questions through qualitative content analysis. Subsequently, the differences between pre-tests and post-tests were found by comparison.

b) By content analysis of individual students' diaries and the categorization of the analyzed data, using OECD framework of specific categories of transversal competencies;

c) By content analysis of projects - course outcomes and of group reports, again focusing on assessing transversal competencies;

d) By analysis of self-reflections, feedbacks, mutual reflections, evaluations of external evaluators.

\subsection{Results from empirical research of the implementation of the GELS course}

The data processed so far through qualitative analysis and comparison confirm the increase of the following competencies:

As it turned out from the analysis of works and presentations of students in a foreign language, as well as from the comparison of pre-tests and post-tests, except for students with an entry level of C2 (according to CEFR, 2018), it is possible to confirm a clear increase in foreign language communicative competence of at least one level, i.e., if the student was initially at the B1+level, the final level was B2- , and so on in other cases, if B2- at the beginning - then at least B2 at the end of the course Most importantly, students themselves noticed an increased fluency in their speaking in a foreign language and 
reduced fear of speaking in it, improved listening skills, and more self-confidence to write about professional matters in a foreign language.

From financial reasons, we did not have access to any standardized framework for assessing intercultural and other transversal competences, but we used the OECD classification (2012) for the qualitative evaluation of their potential increase. Content analysis and comparison of data obtained from all available sources showed an increase in skills and competencies in the following areas (in order of frequency and intensity - starting with the most developed ones):

a) Development of inter-personnel competence;

b) Intercultural competence - increasing the level of knowledge and attitude of tolerance towards other cultures;

c) Critical thinking, problem solving;

d) Willingness to take risks and look for challenges;

e) Ability to work in a team, leadership skills;

f) Project and time management;

g) Project writing, planning, implementation and evaluation;

h) Communication skills - communication with team members, with teachers, with the target community;

i) Written and oral presentation skills;

j) Creativity and ability to think abstractly in project design;

k) Active citizenship.

\subsection{Discussion}

The overview of the results shows that the expectations from the project intention of GELS - to develop, in addition to foreign language competence, also the above-mentioned transferable competencies, have been fulfilled. Although there is no room here to detail them, the analysis so far and especially the student outcomes have shown an increase in all the above-mentioned areas. Service learning strategy. Service learning strategy has proven to be a natural, attractive, effective method of mutual students' learning, enabling their transversal competencies to flourish.

Similarly, Burbach et al. (2004) describe the positive impact of service-learning subjects, namely, e.g., to develop critical thinking. The team around Eyler (2001) compiled a whole list of studies that prove the positive impact of service-learning on personal, social and educational outcomes, as well as on career development and relationships with domestic institutions, namely the impact on:

- personal development (awareness of self-efficacy, personal identity, moral development) and development of interpersonal skills to cooperate, lead, communicate despite differences, belief in the importance of diversity,

- development of the social dimension - social skills, elimination of stereotypes, facilitation of cultural understanding, development of social responsibility and civic skills, willingness to decide to help the community, involvement in the community,

- cognitive but also affective growth - ability to apply the acquired knowledge in practice, critical thinking, ability to solve problems, and others (positive impact on preparation for the profession after graduation).

\section{Conclusion}

In summary, the main idea of this contribution was to present an innovation consisting of the integration of foreign language teaching with the development of transversal competencies, through a new university course using a service-learning strategy. Within it, internationally mixed groups of university students performed analyzes of the specific needs of a specific community, and subsequently prepared projects to meet them.

The whole innovation has been research-proven. The results showed that such a pedagogical strategy, where students had to cooperate, create and be responsible for the results of group work, contributed to the development of their transversal competencies more than in other, traditionally taught language subjects. Although these were small groups of students, and more massive research would certainly be needed, the results of our validation show that it is extremely successful and, in addition, very popular with students and teachers, as it is a natural, independent and cooperative way of learning. 


\section{Acknowledgements}

This study is an integral part of the project 'Plurilingual and intercultural edulab supporting university strategy of internationalization' (KEGA 004UMB-4/2019) supported by the Cultural and Educational Grant Agency of the Ministry of Education, science, research and sport of the Slovak Republic.

\section{References}

Bérešová, J. (2009). Didaktika anglického jazyka. [Methodology of Teaching English Language.] Bratislava, Slovakia: Metodicko-pedagogické centrum.

Burbach, M. E., Matkin, G., Gina, S., \& Fritz, S. M. (2004). Teaching Critical Thinking in an Introductory Leadership Course. College Student Journal, 38(3), 482-493.

Council of Europe. (2018). Common European Framework of Reference for Languages: Learning, Teaching, Assessment. Companion Volume with New Descriptors. Strasbourg: Council of Europe.

EU Commission. (1995). White Paper on Education and Training - Teaching and Learning - Towards the Learning Society. COM (95) 590 final, 29 November 1995. Retrieved May, 4, 2021 from https://europa.eu/documents/comm/white_papers/pdf/com95_590_en.pdf

European Qualifications Framework (EQF). https://ufm.dk/en/education/recognition-andtransparency/transparency-tools/qualifications-frameworks/european-qualifications-framework

Eyler, J., Giles, D. E., Stenson, Ch. M., \& Gray, Ch. J. (2001). At A Glance: What We Know about The Effects of Service-Learning on College Students, Faculty, Institutions and Communities, 1993- 2000. Higher Education. 139. https://digitalcommons.unomaha.edu/slcehighered/139

Hartman, E., \& Kiely, R. (2017). Global Service Learning: Definition, Theoretical Lineages, and Application Efforts. In C. Dolgon, T. Mitchell, \& T. Eatman (Eds.), The Cambridge Handbook of Service Learning and Community Engagement (Cambridge Handbooks in Psychology, pp. 321-334). Cambridge: Cambridge University Press.

Hymes, D. H. (1972). On Communicative Competence. In: J. B. Pride \& J. Holmes. Sociolinguistics. Selected Readings (pp. 269-293). Harmondsworth: Penguin. Retrieved April, 14, 2021 from https://fdocuments.in/document/on-communicative-competence-01-by-dell-hymes.html

Kosová, B., Hanesová, D., Šukolová, D. et al. (2019). Doktorandská škola - cesta k transformácii a inovácii doktorandského vzdelávania vo svete a na Slovensku [Doctoral School - A Way to Transformation and Innovation of Doctoral Education in the World and in Slovakia]. Banská Bystrica: Univerzita Mateja Bela v Banskej Bystrici - Belianum.

Mitchell, T., \& Donahue, D. (2017). Ideal and Real in Service Learning: Transforming the Ideal Based on the Real. In: Dolgon, C., Mitchell, T. \& Eeatman, T. (eds.). The Cambridge Handbook of Service Learning and Community Engagement (pp. 458-469). Cambridge: Cambridge University Press.

Nováková, Zuzana. (2020). Using digital tools to facilitate self-assessment and feedback for the development of students' speaking skills. Prešov: Prešovská univerzita.

OECD. (2012). Transferable Skills Training for Researchers: Supporting Career Development and Research. OECD Publishing, 2012. Retrieved May, 17, 2021 from https://www.oecd.org/science/transferableskills.htm

OECD. (2019). PISA 2018 Assessment and Analytical Framework, Paris: OECD Publishing. Retrieved May, 5, 2021 from https://doi.org/10.1787/b25efab8-en, p. 166

UNESCO. (2013). IBE Glossary of Curriculum Terminology. Geneva: UNESCO International Bureau of Education. Retrieved May, 1, 2021 from http://www.ibe.unesco.org/fileadmin/ user_upload/Publications/IBE_GlossaryCurriculumTerminology2013_eng.pdf; TVETipedia Glossary. UNESCO UNEVOC.

UNESCO. (2015). Asia-Pacific Education Research - Institute Network Regional study on Transversal Competences in Education Policy and Practice. Paris; Bangkok: UNESCO. Retrieved April, 14, 2021 from https://unesdoc.unesco.org/ark:/48223/pf0000231907, S. 2

WEF World Economic Forum. (2016). The Future of the Jobs Employment, Skills and Workforce. Retrieved May, 14, 2021 from http://www3.weforum.org/docs/WEF_Future_of_Jobs.pdf

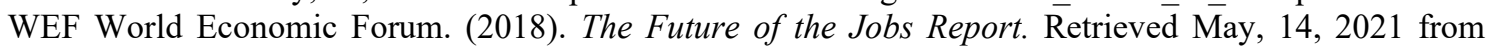
http://www3.weforum.org/docs/WEF_Future_of_Jobs_2018.pdf 